\title{
Article
}

\section{4-Nonylphenol effects on rat testis and sertoli cells determined by spectrochemical techniques coupled with chemometric analysis}

Duan, Peng, Liu, Bisen, Medeiros-De-morais, Camilo De lelis, Zhao, Jing, Li, Xiandong, Tu, Jian, Yang, Weiyingxue, Chen, Chunling, Long, Manman, Feng, Xiaobing, Martin, Francis L and Xiong, Chengliang

Available at http://clok.uclan.ac.uk/24909/

Duan, Peng, Liu, Bisen, Medeiros-De-morais, Camilo De lelis ORCID: 00000003-2573-787X, Zhao, Jing, Li, Xiandong, Tu, Jian, Yang, Weiyingxue, Chen, Chunling, Long, Manman et al (2019) 4-Nonylphenol effects on rat testis and sertoli cells determined by spectrochemical techniques coupled with chemometric analysis. Chemosphere, 218 . pp. 64-75. ISSN 0045-6535

It is advisable to refer to the publisher's version if you intend to cite from the work. http://dx.doi.org/10.1016/j.chemosphere.2018.11.086

For more information about UCLan's research in this area go to http://www.uclan.ac.uk/researchgroups/ and search for < name of research Group>.

For information about Research generally at UCLan please go to http://www.uclan.ac.uk/research/

All outputs in CLoK are protected by Intellectual Property Rights law, including Copyright law. Copyright, IPR and Moral Rights for the works on this site are retained by the individual authors and/or other copyright owners. Terms and conditions for use of this material are defined in the policies page. 
3 Peng Duan ${ }^{1,2}$, Bisen Liu ${ }^{3}$, Camilo L. M. Morais ${ }^{4}$, Jing Zhao ${ }^{5}$, Xiandong $\mathrm{Li}^{6}$, Jian $\mathrm{Tu}^{7}$,

4 Weiyingxue Yang ${ }^{3}$, Chunling $\mathrm{Chen}^{3}$, Manman Long ${ }^{3}$, Xiaobing Feng ${ }^{3}$, Francis L.

5 Martin $^{4, \pi}$, Chengliang Xiong ${ }^{1,8, \uparrow}$

6

4-Nonylphenol effects on rat testis and Sertoli cells determined by spectrochemical techniques coupled with chemometric analysis

${ }^{1}$ Family Planning Research Institute, Tongji Medical College, Huazhong University of Science and Technology, Wuhan 430030, China; ${ }^{2}$ Center for Reproductive Medicine, Xiangyang No. 1 People's Hospital, Hubei University of Medicine, Xiangyang 441000, China; ${ }^{3}$ Department of Epidemiology and Biostatistics, School of Public Health, Tongji Medical College, Huazhong University of Science and Technology, Wuhan, Hubei, China; ${ }^{4}$ School of Pharmacy and Biomedical Sciences, University of Central Lancashire, Preston PRI 2HE, UK; ${ }^{5}$ Department of Epidemiology and Health Statistics, School of Public Health, Medical College, Wuhan University of Science and Technology, Wuhan 430030, China; ${ }^{6}$ Department of Clinical Laboratory, Taihe Hospital, Hubei University of Medicine, Shiyan 442000, China; ${ }^{7}$ Reproductive medicine center, Maternal and Child Health Care Hospital of Yueyang City, Yueyang 414000, China; ${ }^{8}$ Center for Reproductive Medicine, Wuhan Tongji Reproductive Medicine Hospital, 128 Sanyang Road, Wuhan 430013, China

\section{Corresponding authors:}

${ }^{\mathbb{T}}$ Chengliang Xiong, Family Planning Research Institute, Tongji Medical College, Huazhong University of Science and Technology, 13 Hangkong Road, 430030 Wuhan, Hubei Province, China. Tel: +86-0278-83692651; E-mail: clxiong951@sina.com.

${ }^{\mathrm{I}}$ Francis L. Martin, School of Pharmacy and Biomedical Sciences, University of Central Lancashire, Preston PR1 2HE, UK. Tel: +44 (0)-1772 89-6482; E-mail: flmartin@uclan.ac.uk 


\section{Abstract}

Herein, vibrational spectroscopy has been applied for qualitative identification of biomolecular alterations that occur in cells and tissues following chemical treatment. Towards this end, we combined attenuated total reflection Fourier-transform infrared (ATR-FTIR) and Raman spectroscopy to assess testicular toxicology after 4-nonylphenol (NP) exposure, an estrogenic endocrine disruptor affecting testicular function in rats and other species. Rats aged 21, 35 or 50 days received NP at intra-peritoneal doses of $0,25,50$ or $100 \mathrm{mg} / \mathrm{kg}$ for 20 consecutive days. Primary Sertoli cells (SCs) were treated with NP at various concentrations $(0,2.5,5,10$ or 20 $\mu \mathrm{M})$ for $12 \mathrm{~h}$. Post-exposure, testicular cells, interstitial tissue and SCs were interrogated respectively using spectrochemical techniques coupled with multivariate analysis. Distinct biomolecular segregation between the NP-exposed samples vs. control were observed based on infrared (IR) spectral regions of $3200-2800 \mathrm{~cm}^{-1}$ and $1800-900 \mathrm{~cm}^{-1}$, and the Raman spectral region of $1800-900 \mathrm{~cm}^{-1}$. For in vivo experiments, the main wavenumbers responsible for segregation varied significantly among the three age classes. The main IR and Raman band differences between NP-exposed and control groups were observed for Amide (proteins), lipids and DNA/RNA. An interesting finding was that the peptide aggregation level, Amide I-to-Amide II ratio, and phosphate-to-carbohydrate ratio were considerably reduced in ex vivo NP-exposed testicular cells or SCs in vitro. This study demonstrates that ATR-FTIR and Raman spectroscopy techniques can be applied towards analysing NP-induced testicular biomolecular alterations. 
50 Highlights

51 - The extent of testicular damage was assessed by ATR-FTIR and Raman 52 spectroscopy

53 - 4-Nonylphenol (NP) exposure-induced testicular toxicity is associated with 54 biomolecular alterations

55 - The biomolecular alterations by the age at which NP exposure started

56

57

58 Keywords: 4-nonylphenol exposure, testicular toxicity, Sertoli cells, ATR-FTIR 59 60 


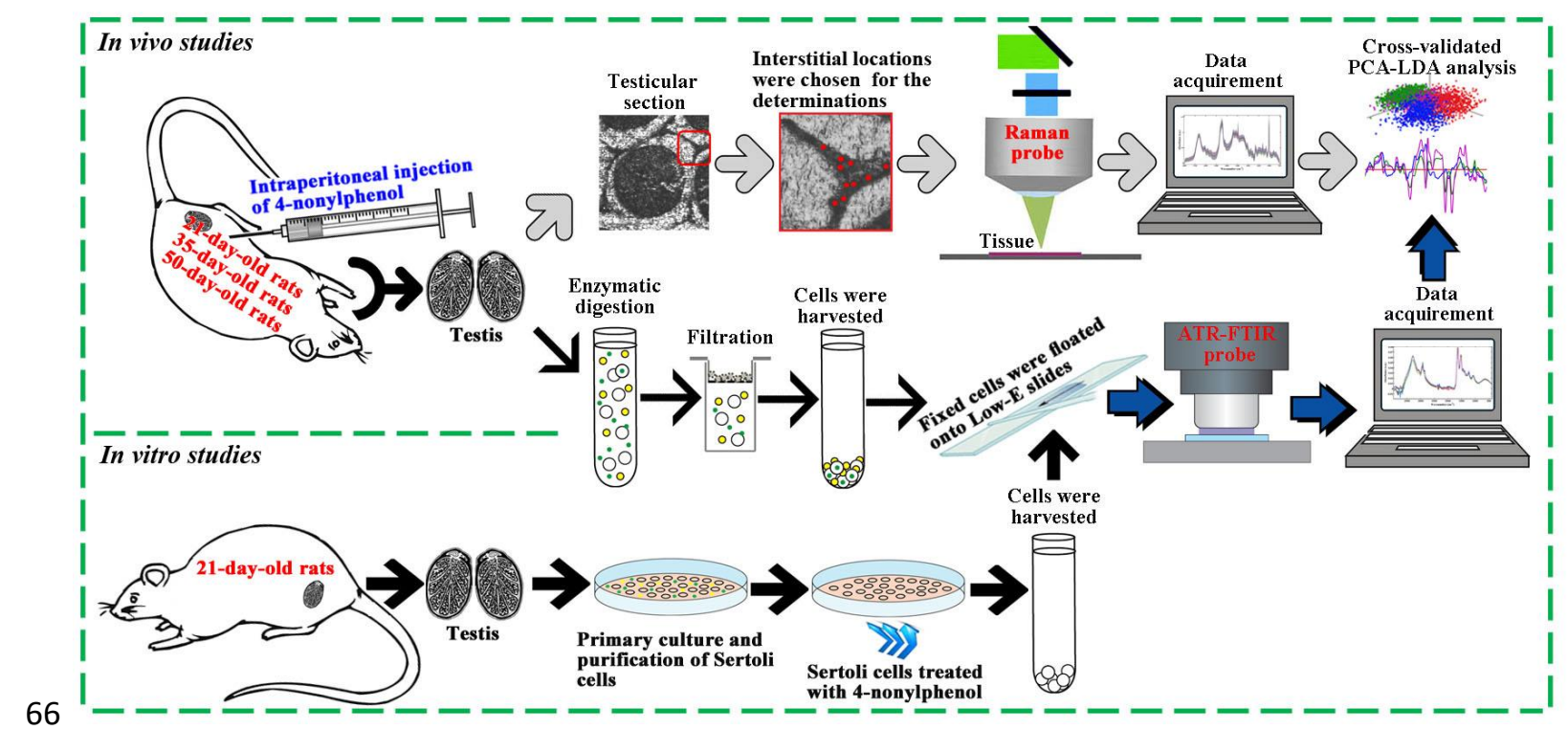




\section{Introduction}

Endocrine disrupting chemicals are natural or synthetic compounds, which are able to interfere with endocrine system and consequently cause various health problems in animals and human beings (Lee et al., 2013). One of the most frequently detected endocrine disrupting chemicals is 4-nonylphenol (NP), an environmental oestrogen-like chemical derived from nonylphenol ethoxylates (NPEOs), which are extensively used as non-surfactants in detergents, emulsifiers, wetting and dispersing agents, and pesticide formulations for the last 40 years (Soares et al., 2008; Iqbal and Bhatti, 2015). NP belongs to category 1 (clear evidence of endocrine disrupting effects in an intact organism) of the endocrine disrupter priority list (Wang et al., 2016). The occurrence of NP has been reported in different environmental compartments worldwide, as well as within humans and other biota (Fairbairn et al., 2016; Staniszewska et al., 2016; Wang et al., 2016; Diao et al., 2017; Lin et al., 2017; Peng et al., 2017). According to a study conducted in the Zumbro River watershed of United States, the concentration of NP was up to $10^{4} \mathrm{ng} / \mathrm{L}$ (Fairbairn et al., 2016). In the Pearl River Estuary of China, NP was identified at concentrations ranging from 233.04 to $3352.86 \mathrm{ng} / \mathrm{L}$ in surface water and 7.55 to $20.80 \mathrm{ng} / \mathrm{g}$ of dry weight (dw) in sediment (Diao et al., 2017). As regards exposure to wildlife and humans, high NP levels $(111.2 \mathrm{ng} / \mathrm{g} \mathrm{dw})$ were determined in zooplankton off the Gulf of Gdansk (Southern Baltic) in the years 2011-2012 and, additionally, NP was found in cord blood plasma with a median concentration of $72.6 \mathrm{ng} / \mathrm{mL}$ in 208 children from Taiwan (Staniszewska et al., 2016; Lin et al., 2017). NP has also been detected in food, such as cereals and vegetables (Aparicio et al., 2017; Pastor-Belda et al., 2017). Due to its ubiquitous presence and known estrogenomimetic properties, there is a growing concern regarding the environmental fate and potential impacts of NP on human and ecosystem health (Li et al., 2013b).

NP has been found in various human tissues (Deng et al., 2010; Asimakopoulos et al., 2012) and to cause a wide range of reproductive and developmental toxicities in fish and mammals (Chapin et al., 1999; El-Sayed Ali et al., 2014; Duan et al., 2016a; 
Duan et al., 2017b). Male reproductive system toxicity is one of the prominent adverse effects of NP (Noorimotlagh et al., 2017). Evidence that NP could exert estrogenic actions and disturb hormonal homeostasis has arisen from studies in male rats models (Chapin et al., 1999; Duan et al., 2017a). Our previous studies found that pre-pubertal exposure to NP in rats induced reproductive dysfunction during adulthood (Duan et al., 2016a; Huang et al., 2016). NP treatment affects spermatogenesis, sperm function and morphology (El-Sayed Ali et al., 2014; Cheng et al., 2017; Duan et al., 2017a). When treated with $\geq 50 \mathrm{mg} \mathrm{NP} / \mathrm{kg}$, the seminiferous tubules exhibit a hollow tendency and the levels of apoptosis of testicular cells increase (Duan et al., 2016a; Huang et al., 2016; Duan et al., 2017a). NP has been shown to trigger apoptosis and autophagy in Sertoli cells (Huang et al., 2016; Duan et al., 2017b; Su et al., 2018). Additionally, Jambor et al confirmed the inhibitory effects of $5.0 \mathrm{mg} \mathrm{NP} / \mathrm{mL}$ on mice Leydig cells in vitro (Jambor et al., 2017). The results of these studies converge to suggest that NP is a potent testicular toxicant. The multiple mechanisms responsible for testicular toxicity of NP involve oxidative stress, modulation of MAPK/Akt/AMPK/mTOR signalling, autophagic and apoptotic pathways (Liu et al., 2014; Duan et al., 2016b; Huang et al., 2016). Of note, the evidence of direct association between NP exposure and alterations in the biomolecular signatures of testicular cells remain limited.

Vibrational spectroscopy has attracted growing attention as a bio-analytical tool for biomedical research. The most commonly used methods include Fourier-transform infrared (FTIR) in transmission, transflectance or reflection modes; and Raman spectroscopy (Owens et al., 2014). Attenuated total reflection (ATR)-FTIR or Raman spectroscopies have many advantages over traditional molecular biology techniques (e.g., ELISA, Western blotting, RT-PCR), since they are able to analyse samples in a non-destructive and label-free manner (Andrew Chan and Kazarian, 2016; Butler et al., 2016; Paraskevaidi et al., 2017b), with minimal sample preparation (Butler et al., 2016; Obinaju and Martin, 2016), and allowing a simultaneous analysis of a wide range of different biomolecules (Paraskevaidi et al., 2017b). In the past few years, 
ATR-FTIR and Raman spectroscopy have been extensively applied in toxicology studies, including in vivo (Chen et al., 2015; Li et al., 2015; Obinaju and Martin, 2016) and in vitro tests (Obinaju et al., 2015; Li et al., 2016; Strong et al., 2016). In addition, their potential for disease diagnosis has also been demonstrated in many publications (Gajjar et al., 2012; Owens et al., 2014; Lima et al., 2015; Paraskevaidi et al., 2017b).

ATR-FTIR spectroscopy measures the energy absorbed by functional groups within a sample after exposure to IR radiation and generates a spectrum with peaks related to chemical structure of particular entities, e.g., lipids $\sim 1740 \mathrm{~cm}^{-1}$, DNA $\sim 1080 \mathrm{~cm}^{-1}$, Amide I and II $\sim 1650$ and $1550 \mathrm{~cm}^{-1}$, respectively. Such entities are mainly present in the $1800-900 \mathrm{~cm}^{-1}$ region (known as the "biochemical fingerprint" region) (Li et al., 2016; Strong et al., 2016). In contrast, Raman spectroscopy exploits the phenomena of inelastic scattering to detect chemical bonds (Butler et al., 2016). Using Raman microspectroscopy, it is possible to image individual cells on the subcellular level (Eberhardt et al., 2015), making it an excellent technique to detect alterations in specific cells. The combined application of ATR-FTIR and Raman spectroscopy can offer complementary structural information about the same sample.

Therefore, in the present study, both ATR-FTIR and Raman spectroscopy were employed to detect biomolecular alterations in testis from NP-treated rats of different ages and NP-treated sertoli cells in vitro. Following spectroscopic measurements, spectral data were analysed using principal component analysis followed by linear discriminant analysis (PCA-LDA), which generates scores plots in two- or three-dimensional spaces and allows the construction of cluster vectors (Heppenstall et al., 2013) for data visualization. The aim of this study was to determine the NP-induced effects on biomolecular parameters of testis in a dose- and age-related manner.

\section{Materials and methods}


Primary Sertoli cell (SC) cultures were prepared from testis of 18- to 21-day-old rat, as previously described (Duan et al., 2016b; Duan et al., 2017b), with modifications. Briefly, testis were digested in DMEM/F12 (1:1) medium (Hyclone, USA) containing $0.25 \%$ trypsin (Sigma, USA) and $0.5 \mathrm{mg} / \mathrm{mL}$ Deoxyribonuclease I (DNase I) (Sigma, USA) for $30 \mathrm{~min}$ with 75 cycles/min shaking in a water bath at $37^{\circ} \mathrm{C}$. The digested tissues were centrifuged and washed with D-Hanks twice, and the washed tubular pellets were suspended in DMEM/F12 medium containing $1 \mathrm{mg} / \mathrm{mL}$ collagenase I, 0.5 $\mathrm{mg} / \mathrm{mL}$ DNase I and $1 \mathrm{mg} / \mathrm{mL}$ hyaluronidase (Sigma, USA) at $37^{\circ} \mathrm{C}$ for $20 \mathrm{~min}$ with 120 cycles/min shaking. Thereafter, the suspension was filtered through a 200-mesh cell sieve and the cells were washed twice with D-Hanks. Primary cells were re-suspended in DMEM/F12 medium supplemented with $1 \%$ penicillin-streptomycin (Beyotime, China) and seeded in 6-well plates at a density of $1 \times 10^{6}$ cells per well. Cells were maintained in a humidified atmosphere of $95 \%$ air $-5 \% \mathrm{CO}_{2}$ at $35^{\circ} \mathrm{C}$ and the serum-free medium was changed at $24 \mathrm{~h}$ intervals. On Day 3 of culture, contaminating spermatogenic cells were lysed with a hypotonic solution of $20 \mathrm{mM}$

\subsection{Exposure treatments and cell viability}

NP (CAS no. 84852-15-3) (Leicestershire, UK) was dissolved in dimethylsulfoxide (DMSO) (Sigma, USA) as stock solution and diluted with DMEM/F12 (1:1) medium to different concentrations before being added to the SCs in culture. The final DMSO concentration in the medium was not more than $0.1 \%(\mathrm{v} / \mathrm{v})$, which did not affect the viability of SCs. Control SCs were cultured with $0.1 \%$ DMSO. 
previous studies (Duan et al., 2016b; Huang et al., 2016; Duan et al., 2017b). SCs were seeded in a 96-well plate and treated with various concentrations of NP $(0,2.5,5$, 10 or $20 \mu \mathrm{M}$ ) for 6,12 or $24 \mathrm{~h}$. Cellular viability was assessed using a CCK-8 kit (Beyotime, Shanghai, China), as previously mentioned (Duan et al., 2016b). Cell viability index was calculated using the following formula:

$$
\text { Cell viability } \%=\left[\left(\mathrm{A}_{450} \text { sample }- \text { background }\right) /(\mathrm{A} 450 \text { control }- \text { background })\right] \times
$$
$100 \%$

\section{Each experiment was repeated six times.}

\subsection{Sertoli cell preparation for ATR-FTIR spectroscopy}

After treatment with different concentrations of NP for $12 \mathrm{~h}$, the cells were washed with D-Hanks, trypsinized, and centrifuged at $800 \mathrm{rpm}$ for 5 minutes at $4^{\circ} \mathrm{C}$. Following this, cell pellets were immediately re-suspended in $4 \%$ paraformaldehyde (PFA) (Beyotime, China) for $30 \mathrm{~min}$, washed with D-Hanks twice, floated onto infrared-reflective Low-E glass slides (Kevley Technologies, USA), and then air-dried at room temperature for $24 \mathrm{~h}$ before ATR-FTIR spectroscopy. The experiments were repeated six times for each NP treatment.

\subsection{Animal experiment protocol and sample collection}

Male Sprague-Dawley (SD) rats were obtained from Tongji Medical College Animal Centre (Wuhan, China). All rats were housed in a specific pathogen-free animal facility with unrestricted access to standard rodent chow diet and tap water in experimental animal centre of Tongji Medical College (Wuhan, China). The animal facility conditions were as follows: temperature $22 \pm 2^{\circ} \mathrm{C}$; humidity $60 \pm 5 \%$; artificial 12:12-h light-dark cycle: light on at 06:00 am. All experimental procedures involving the use of rats in this study were reviewed and approved by the Animal Care and Use Committee of Tongji Medical College, Huazhong University of Science and Technology. 
Pre-puberty is considered the critical time for male sexual differentiation in the SD rat (Lu et al., 2016). Most cells in the seminiferous tubules at pre-puberty are Sertoli cells. Adolescence is a unique period of enhanced vulnerability to the reproductive toxicity caused by endocrine disrupting chemicals because of their interference effects on the onset of spermatogenesis. The entire process of spermatogenesis is newly established during the period of young adulthood. To explore the effects of NP on the biomolecular composition of testicular cells at different age stages, in the present study, NP dissolved in corn oil (Sigma, USA) free of antioxidants was intraperitoneally injected into prepuberty (21 days), peri-adolescent (35 days) and young adult (50 days) rats. Twenty-four rats from each age-class were divided randomly into four groups consisting of six rats each: vehicle control group (only corn oil), low-dose NP group (25 mg/kg body weight), middle-dose NP group (50 mg/kg body weight) and high-dose NP group (100 mg/kg body weight). The injections were administered from 8:30 am to 11:30 am every other day for 20 consecutive days. These doses and times were chosen on the basis of previous studies (Duan et al., 2016a; 2017a; Huang et al., 2016). The dosing volume was set at $5 \mathrm{ml} / \mathrm{kg}$ body weight in all groups. Body weights of each rat were recorded before NP administration.

Two days after the last injections, all animals were weighted and sacrificed by decapitation, their testes were dissected out and immediately weighed for calculation of testis index. The left testis of each rat was used for haematoxylin and eosin (H\&E) staining and spectroscopic analysis, and the right testis were flash-frozen in liquid nitrogen and then stored at $80^{\circ} \mathrm{C}$ until use.

\subsection{ATR-FTIR spectroscopic analysis of Sertoli cells and testicular cells}

Cell samples on Low-E glass slides were analysed using a Tensor 27 FTIR spectrometer equipped with a Helios ATR attachment containing a diamond crystal $(\sim 250 \times 250 \mu \mathrm{m}$ sampling area) (Bruker Optics Ltd., Coventry, UK). The details of operation procedure and spectral acquisition were the same as our previous reports (Baker et al., 2014; Jin et al., 2017; Paraskevaidi et al., 2017b). Briefly, the parameters 
for recording the IR spectra were set at spectral range of $4000-400 \mathrm{~cm}^{-1}, 32$ co-added scans, $8 \mathrm{~cm}^{-1}$ resolution and $2 \times$ zero-filling to maximize the signal-to-noise ratio. Ten spectra were acquired from different sites of each cell sample to minimize bias. The ATR crystal was cleaned with distilled water and dried with soft tissue, and a new background spectrum was taken prior the measurement of each next cell sample. Subsequently, spectra were converted to absorbance using Bruker OPUS software. IR spectra were pre-processed using IRootLab toolbox (http://trevisanj.github.io/irootlab/) running on MATLAB R2010a (The MathWorks, Inc., US) (Baker et al., 2014; Paraskevaidi et al., 2017b). Raw spectra were cut, baseline-corrected and normalized over the $3500-750 \mathrm{~cm}^{-1}$ region.

\subsection{Tissue section preparation for Raman spectroscopic analysis}

The half-left testis of each rat were fixed in $4 \%$ PFA at $4^{\circ} \mathrm{C}$ overnight, embedded in paraffin, sectioned for $10 \mu \mathrm{m}$ thickness and then transferred onto a slide covered with aluminum foil (Li et al., 2017). The paraffin-embedded testicular sections were routinely de-paraffinized with xylene and a graded series of ethanol $(100 \%, 90 \%, 80 \%$ and $70 \%$ ) for $2 \mathrm{~min}$ each. Testicular sections were air-dried at room temperature for $24 \mathrm{~h}$ and analysed by Raman spectroscopy. Raman spectra of testicular interstitial tissue were recorded using an InVia Renishaw Raman spectrometer with a $785 \mathrm{~nm}$ diode laser (Renishaw plc, UK), which has recently been described in more detail (Butler et al., 2016; Li et al., 2017). Briefly, the Raman system was calibrated using the $520 \mathrm{~cm}^{-1}$ band of a silicon wafer for assessing wavenumber shifts. An attached microscope (Leica Microsystems, Milton Keynes, UK) with $\times 50$ objective $(0.75$ numerical aperture; $\sim 1 \mu \mathrm{m}$ spatial resolution) was utilized for point-mapping of interstitial tissue. All point spectra were collected using 100\% laser power (26 mW at sample), $15 \mathrm{~s}$ exposure time and 1 accumulation within the $1800 \sim 900 \mathrm{~cm}^{-1}$ spectral range, and approximately 100 spectra were obtained from different sites of testicular interstitial tissue from each rat. Each acquired raw spectrum was pre-processed by rubberband baseline correction and normalization to the Amide I peak using MATLAB (Butler et al., 2016; Li et al., 2017). 


\subsection{Multivariate data analysis}

268

269

270

271

272

273

274

275

276

277

278

After pre-processing, principal component analysis coupled with linear discriminant analysis (PCA-LDA) was applied to the resulting dataset to identify between-category segregation. The output data derived from PCA-LDA were extracted and represented in the form of scores plots and cluster vectors. PCA-LDA cluster vectors were developed to identify the distinguishing wavenumbers responsible for separating the control from the other categories (Riding et al., 2012; Li et al., 2013a). Herein, the NP-induced biomolecular alterations were determined by setting the control at the origin with a zero coefficient value, which represented no biochemical alteration. One cluster vector was generated through the mean of each group. For the cluster vectors of all NP treatment groups $v s$. the corresponding control (line at origin), the extent of peak deviation away from the origin is proportional to the extent of biomolecular alteration. In this case, we were able to detect the prominent wavenumbers that mainly contributed to category segregation and then explain biomolecular differences between NP-treated vs. control groups. PCA-LDA-based spectral classification was performed using leave-one-out cross-validation as previously described (Li et al., 2015; Paraskevaidi et al., 2017b).

\subsection{Statistical analysis}

The results were expressed as the means \pm standard deviation (SD). Statistical analysis across multiple groups was performed using a one-way analysis of variance (ANOVA), followed by Fisher's LSD post-hoc test for homogeneity of variance and Dunnett's T3 post-hoc test for heterogeneity of variance. The effects of both NP concentrations and exposure age, as independent factors, and the interaction effects between the factors were tested by two-way ANOVA. All significance testing were carried out in SPSS software version 12.0 (SPSS, Chicago, IL, USA). Two-sided $P$-values of $<0.05$ and $<0.001$ were considered as statistically significant or highly significant, respectively. Scatter plots and bar graphs were done using GraphPad PRISM Version 4.0 (San Diego, CA, USA). 


\section{Results}

\subsection{General and histopathological observations}

297

No mortality was observed in any of the treatment groups. As shown in ESI Figure S2, prepubertal, periadolescent and young adult exposure to NP did not affect final body weights, weight gain, testis weights or testis coefficient of rats with different ages $(P>0.05)$. No interaction effects between NP concentrations and NP-exposure life stages were observed regarding organ coefficient of testis (two-way ANOVA, $\left.P_{\text {interaction }}=0.551\right)$; however, age was a significant factor (effect of ages $\left.P<0.001\right)$ (see ESI Figure S3). Body weights, measured at each time point between Day 0 and 20, were similar in NP-exposed and corresponding control animals $(P>0.05$, data not shown).

Testicular tissues of the control group within each age subgroup exhibited intact architecture with well-organized seminiferous tubules, while those from rats exposed to NP showed dose-dependent degenerative histological changes in the tubules in the form of vacuolation and loss of normal tubular architecture (see ESI Figure S4).

\subsection{ATR-FTIR spectroscopy detects NP-induced biomolecular alterations in testis cells}

Herein, the IR spectral regions processed included the biochemical-cell fingerprint region $\left(1800-900 \mathrm{~cm}^{-1}\right)$ and the lipid region $\left(3200-2800 \mathrm{~cm}^{-1}\right)$ [ESI Figure S5]. The between-class covariance matrix using spectral data of these two regions highlights the structural and compositional variations of testicular cells between the NP-treated and control groups within each age-class (see ESI Figure S6). Projection of the spectral points in three-dimensional (3-D) spaces enables visualization of clustering patterns among categories. Cluster segregation between NP-treated and control categories at different age-classes is apparent in both $1800-900 \mathrm{~cm}^{-1}$ region (Figure 1A) and 3200-2800 $\mathrm{cm}^{-1}$ region (Figure 1B).

Scores on linear discriminant 1 (LD1) space contain most of the variance in the spectral data and allow observation of a dose-response relationship. Figure 1C-D 
shows that in all treatment groups, the NP-induced effects observed exhibit a dose-related response and differed significantly from the corresponding control group $(P<0.001)$, except the $25 \mathrm{mg} \mathrm{NP} / \mathrm{kg}$ treatment within the 50-day-old class at the lipid region $(P>0.05)$. Two-way ANOVA demonstrates significant interaction effects between NP concentrations and NP-exposure life stages with respect to LD1 scores of both the $1800-900 \mathrm{~cm}^{-1}$ and $3200-2800 \mathrm{~cm}^{-1}$ regions $(P<0.001)$ (see ESI Figure S7). Interestingly, there was no marked effect of age on the LD1 change of $3200-2800 \mathrm{~cm}^{-1}$ region (effect of ages $P=0.154$ ).

The derived cluster vectors plots comparing NP-treated rats to control in testicular cells show NP-induced changes associated with distinguishing IR wavenumbers (Figure 2). The IR peaks at $1200 \mathrm{~cm}^{-1}$ (collagen), $1416 \mathrm{~cm}^{-1}$ (proteins), $1481 \mathrm{~cm}^{-1}$ (protein conformation), $1504 \mathrm{~cm}^{-1}$ (Amide II), $1670 \mathrm{~cm}^{-1}$ (Amide I), and those associated with $\mathrm{CH}$ stretching vibrations of lipids $\left(2816,3028\right.$ and $\left.3090 \mathrm{~cm}^{-1}\right)$ were identified by the peak detector and are included in the cluster vectors plot of 21-day-old class (Figure 2A). From the cluster vectors plot of the 35-day-old class (Figure 2B), there are highlighted IR peaks at $1111 \mathrm{~cm}^{-1}$ (RNA), $1207 \mathrm{~cm}^{-1}$ (collagen), $1308 \mathrm{~cm}^{-1}$ (Amide III), $1534 \mathrm{~cm}^{-1}$ (modified guanine, Amide II), $1582 \mathrm{~cm}^{-1}$ (Amide II), $1667 \mathrm{~cm}^{-1}$ (Amide I $\beta$-turns of proteins), $1732 \mathrm{~cm}^{-1}$ (fatty acids) and $3055 \mathrm{~cm}^{-1}$ (stretching C-H). As depicted for the 50-day-old class in Figure 2C, distinguishing IR wavenumbers include $1234 \mathrm{~cm}^{-1}$ [asymmetric $\mathrm{PO}_{2}^{-}$(Nucleic acid)], $1319 \mathrm{~cm}^{-1}$ (Amide III), $1416 \mathrm{~cm}^{-1}$ (proteins), $1497 \mathrm{~cm}^{-1}$ (Amide II), $1616 \mathrm{~cm}^{-1}$ (Amide I), $1667 \mathrm{~cm}^{-1}$ (Amide I $\beta$-turns of proteins), $2893 \mathrm{~cm}^{-1}\left(\mathrm{CH}_{3}\right.$ symmetric stretching) and $3078 \mathrm{~cm}^{-1}$ (Amide B, Stretching C-H). Furthermore, we observed a great variability in the peak absorbance at various IR wavenumbers mentioned above for each NP treatment within 35-day-old class and for $100 \mathrm{mg} / \mathrm{kg} \mathrm{NP}$ exposure within 21- or 50-day-old classes (see ESI Figure S8), which suggests the effects of NP varied with different age stages.

To further explore the potential toxic effects of NP on testicular cell functions, the IR absorbance ratios were calculated, which can be used to describe the structural 
and compositional changes in biomolecules. As shown in Figure $\mathbf{3 A}$, the lipid-to-protein ratios of high-dose $(50 \mathrm{mg} / \mathrm{kg}$ and $100 \mathrm{mg} / \mathrm{kg}) \mathrm{NP}$ exposures are much higher than those of the control within the 50-day-old class but much lower within both 21 - and 35-day-old classes $(P<0.01)$. In case of the peptide aggregation (Figure 3B), remarked decreases were found in $50 \mathrm{mg} / \mathrm{kg}$ and $100 \mathrm{mg} / \mathrm{kg} \mathrm{NP}$ exposure for 21-, 35- and 50-day-old rats $(P<0.05)$. The $50 \mathrm{mg} / \mathrm{kg}$ and $100 \mathrm{mg} / \mathrm{kg}$ NP-treated rats show a significant decrease in the ratios of Amide I-to-Amide II compared to the control rats within 21 - and 35-day-old classes $(P<0.001)$, but the 50-day-old class show no obvious differences among all NP treatments in this respect $(P>0.05)$ (Figure 3C). The $50 \mathrm{mg} / \mathrm{kg}$ and $100 \mathrm{mg} / \mathrm{kg}$ NP treatments in 21- and 35-day-old rats exhibit much lower ratios of phosphate-to-carbohydrate in comparison with the control $(P<0.001)$, except the 50-day-old rats (Figure 3D). In addition, we reveal a significant interaction between NP concentrations and age classes that influence these parameters (two-way ANOVA, $P_{\text {interaction }}<0.001$ ) (see ESI Figure S9). Also, the exposure life-stage was an independent factor affecting NP-induced biomolecular alterations in testicular cells (effect of ages $P<0.01$ ).

\subsection{Raman spectroscopy detects biomolecular alterations in testicular interstitial tissues of NP-exposed rats}

Herein, Raman spectra of testicular interstitial tissue were recorded in the spectral region from 1800-900 $\mathrm{cm}^{-1}$ (see ESI Figure S10). By performing PCA-LDA model for classification, we are able to visualize clear segregation among different NP-treatment categories of all age-classes (Figure 4A-C). Meanwhile, the main absorption variations between NP-treated and control groups within each age-class were observed by applying between-class covariance matrix (see ESI Figure S11), reflecting NP-induced biomolecular alterations in testicular interstitial cells. Along LD1 dimension, testicular interstitial tissue of differently aged NP-treated rats segregate away from the control, and these differences are statistically significant for all age-classes $(P<0.001)$ (Figure 4D-F). There is a significant main effect of NP treatment, exposure age, and interaction between these two factors on differences in 
LD1 value compared with control group (two-way ANOVA, all $P<0.001$ ) (see ESI Figure S12).

Cluster vectors plots derived from the LD1 space denotes where the differences between NP-treated and control categories of 21-day-old rats are apparent, with prominent Raman wavenumbers at $997 \mathrm{~cm}^{-1}$ (phospholipids, glucose-I-phosphate), $1007 \mathrm{~cm}^{-1}$ (phenylalanine, carbamide), $1131 \mathrm{~cm}^{-1}$ (palmitic acid, fatty acid, C-C skeletal stretching), $1200 \mathrm{~cm}^{-1}$ (nucleic acids, phosphates), $1296 \mathrm{~cm}^{-1}$ (fatty acids), $1465 \mathrm{~cm}^{-1}$ (lipids), $1650 \mathrm{~cm}^{-1}(\mathrm{C}=\mathrm{C}=\mathrm{C}$ bonds in unsaturated fatty acids of phospholipids) and $1675 \mathrm{~cm}^{-1}$ (Amide I) (Figure 4G). From the cluster vectors plot of the 35-day-old class (Figure 4H), there are highlighted peaks at $918 \mathrm{~cm}^{-1}$ (glycogen, lactic acid), $997 \mathrm{~cm}^{-1}$ (phospholipids, glucose-I-phosphate), $1007 \mathrm{~cm}^{-1}$ (phenylalanine, carbamide), $1200 \mathrm{~cm}^{-1}$ (nucleic acids, phosphates), $1346 \mathrm{~cm}^{-1}$ (Amide III vibrations of protein and $\mathrm{CH}$ deformation of protein and lipid), $1465 \mathrm{~cm}^{-1}$ (lipids), as well as the peak associated with Amide I (1647 and $\left.1689 \mathrm{~cm}^{-1}\right)$. As depicted for the 50-day-old group in Figure 4I, distinguishing wavenumbers include $1090 \mathrm{~cm}^{-1}$ (lipids), 1142 $\mathrm{cm}^{-1}$ (Sphingomyelin), $1184 \mathrm{~cm}^{-1}$ [DNA (cytosine, guanine and adenine)], $1307 \mathrm{~cm}^{-1}$ $\left(\mathrm{CH}_{3} / \mathrm{CH}_{2}\right.$ twisting or bending mode of lipid/collagen), $1334 \mathrm{~cm}^{-1}$ (DNA), $1402 \mathrm{~cm}^{-1}$ (collagen, the $\mathrm{CH}_{3}$ symmetric deformation vibrations), $1485 \mathrm{~cm}^{-1}$ (nucleotide acid purine bases), and $1584 \mathrm{~cm}^{-1}$ [pyrimidine ring (nucleic acids), heme protein/ $\mathrm{C}=\mathrm{C}$ phenylalanine]. In addition, there is a significant difference in the peak absorbance of above-mentioned Raman wavenumbers between NP-treated and control groups at different age-classes (see ESI Figure S13).

In addition, the ratio of protein-to-lipid significantly changed in each NP-treatment $v s$. control for all age-classes $(P<0.05)$, except $50 \mathrm{mg} / \mathrm{kg}$ NP exposure for 35-day-old rats (Figure 5A). In the case of unsaturated lipids level, only $50 \mathrm{mg} / \mathrm{kg}$ NP exposure for 35- and 50-day-old rats exhibit no statistical differences in comparison to the corresponding control $(P>0.05)$ (Figure 5B). As shown in Figure $\mathbf{5 C}$, the saturated lipids levels of the $50 \mathrm{mg} / \mathrm{kg}$ and $100 \mathrm{mg} / \mathrm{kg} \mathrm{NP}$ groups are much higher than the control group within the 21-day-old class but much lower within both 
35- and 50-day-old classes $(P<0.05)$. Two way ANOVA reveals the main significant effects of age, NP treatment and a significant interaction between both factors for these ratios change $(P<0.001)$ (see ESI Figure S14).

\subsection{Impact of NP on cell viability in Sertoli cells}

The CCK-8 assay reveals that exposure of SCs to NP $(2.5-20 \mu \mathrm{M})$ reduced cell viability in a dose- and time-dependent manner (see ESI Figure S15). In particular, SCs treated with 10 and $20 \mu \mathrm{M}$ NP exhibited significantly decreased cell viability when compared with control $(0 \mu \mathrm{M} \mathrm{NP})$, respectively, after incubation for $12 \mathrm{~h}$ and 24 $\mathrm{h}(P<0.05)$. In subsequent experiments, we chose $12 \mathrm{~h}$ as the end timepoint for ATR-FITR spectral measurements.

\subsection{ATR-FITR spectroscopy detects biochemical changes in NP-treated Sertoli cells (SCs) in vitro}

The IR spectral regions we investigated are the biochemical-cell fingerprint region $\left(1800-900 \mathrm{~cm}^{-1}\right)$ and the lipid region $\left(3200-2800 \mathrm{~cm}^{-1}\right)$ (see ESI Figure S16). Five clusters for $0,2.5,5,10$ and $20 \mu \mathrm{M}$ NP-treated SCs are well delineated on each 2D PCA-LDA scores plot [LD1 vs. Linear discriminant 2 (LD2)], showing clear cluster separations, with no overlap of the $20 \mu \mathrm{M}$ NP-treatment with the control group in the 1800-900 $\mathrm{cm}^{-1}$ region (Figure 6A), but total overlap of the $2.5 \mu \mathrm{M}$ NP-treatment with the control group in the $3200-2800 \mathrm{~cm}^{-1}$ region (Figure 6B). As shown in Figure 6C-D, NP-induced effects observed in LD1 space exhibit significant differences between each NP-treatment and the control groups in both $1800-900 \mathrm{~cm}^{-1}$ and 3200-2800 $\mathrm{cm}^{-1}$ regions $(P<0.001)$. Interestingly, the dose-response of SCs treated with increasing concentrations of NP is nonlinear and varies markedly between these two regions.

Cluster vectors after PCA-LDA derived from the targeted regions to identify wavenumbers segregating control SCs from NP-treated SCs categories are depicted in Figure 6E-F. The fingerprint region shows prominent peaks at $999 \mathrm{~cm}^{-1}(\mathrm{C}-\mathrm{C}$ stretching of DNA), $1535 \mathrm{~cm}^{-1}$ (Amide II), $1605 \mathrm{~cm}^{-1}$ [DNA, $\left.\delta(\mathrm{NH} 2)\right]$ and $1708 \mathrm{~cm}^{-1}$ 
(A-DNA base pairing vibration) (Figure 6E); statistical significances for absorbance values of these wavenumbers are observed only between $20 \mu \mathrm{M}$ NP-treated and control SCs (see ESI Figure S17). The lipid region generated distinguishing peaks at $2821 \mathrm{~cm}^{-1}$ (stretching C-H), $2975 \mathrm{~cm}^{-1}$ (stretching $\mathrm{N}-\mathrm{H}$, stretching C-H), $3015 \mathrm{~cm}^{-1}$ $\left[v(=\mathrm{CH})\right.$ of lipids] and $3050 \mathrm{~cm}^{-1}$ [Amid B (N-H stretching)] (Figure 6F), and there are significant differences in absorbance of these wavenumbers between NP-treated and control groups, except for $10 \mu \mathrm{M}$ NP-treated SCs (see ESI Figure S17). Notably, these band variations correlate well with the spatial distribution patterns observed using between-class covariance matrix (see ESI Figure S18). As shown in Figure 7, SCs treated with $10 \mu \mathrm{M}$ or $20 \mu \mathrm{M}$ NP exhibit much higher lipid-to-protein ratios and much lower peptide aggregation levels than the control SCs $(P<0.01)$. In addition, NP induced significant decreases of Amide I-to-Amide II ratio and phosphate-to-carbohydrate ratio in comparison to control SCs $(P<0.01)$.

\section{Discussion}

The primary aim of the present study was to apply ATR-FTIR and Raman spectroscopy to monitor the testicular biomolecular changes induced by exposure of male rats aged 21, 35 or 50 days to NP. While IR spectra obtained from testicular cells or SCs can be used to distinguish between the control vs. NP-treated groups, by employing Raman spectroscopy to analyse the interstitial tissue, clear differences between treated and untreated animals are observed, supporting the notion that NP exposure results in testicular toxicity. The results obtained by means of spectrochemical investigations highlight the major differences in the peak intensities assigned to proteins, lipids and nucleic acids that may be responsible for some of the NP-induced effects on spermatogenesis. In addition, an age $\times$ NP treatment interaction was also detected for LD1 score and intensity ratios of the main spectral components.

A balance of the metabolism of lipid and protein in testicular cells is crucial for normal spermatogenesis and membrane remodelling in developing germ cells. Herein, successful differentiation in the fingerprint and lipid $\mathrm{C}-\mathrm{H}$ regions (Figure 1A-B and 6A-B) confirm effects of NP on in vivo testis and in vitro primary SCs. Moreover, 
profound differences are observed in spectral peaks assigned to fatty acids/lipids and amide in proteins. Fatty acids and amide absorptions are mainly associated with the outer cell membrane, and the large spectral alterations associated with lipid content and conformational protein alterations could point to the disruption of the cell membrane structure and integrity (Strong et al., 2016). The lipid/protein ratio was frequently used to identify molecular and compositional changes within tissues. Significant alterations are observed in the lipid-to-protein ratio for the NP-treated samples (Figure 3A and 7A), indicating an alteration in the cellular lipid and protein metabolism caused by NP exposure (Yonar et al., 2018). These biomolecular alterations, in turn, may be related to NP-induced apoptosis or dysfunction of SCs and germ cells that lead to seminiferous tubule degeneration with impaired spermatogenesis.

The alterations of protein-secondary structure inside the targeted cells have been identified as the cause of cell death, either by necrosis or apoptosis (Yousef et al., 2016). The Amide I and II bands are the most prominent vibrational bands of the protein backbone and a sensitive indicator of conformational changes of secondary structure of proteins. The Amide I-to-Amide II ratio describes variation in the overall molecular structures of proteins. In our study, the characteristic bands for Amide I, Amide II, and Amide III are clearly observed. Simultaneously, the values of Amide I-to-Amide II ratios are remarkably decreased for NP-treated SCs and rats aged 21 or 35 days, compared to the control (Figure 3C and 7C). These findings, which suggest protein conformational changes in testicular cells and SCs after exposed to NP, are also consistent with those of other studies showing that NP is able to induce apoptosis in testicular cells in vivo and in SCs in vitro (Wu et al., 2009; Duan et al., 2016a; Duan et al., 2016b; Huang et al., 2016). The modifications of Amide I and II could predict the occurrence of protein aggregation from protein oxidation (Xin et al., 2017). We observed marked decreases in protein aggregation in testicular cells and SCs in response to NP treatment (Figure 3B and 7B). Indeed, exposure to NP induces oxidative stress in testicular tissue and SCs, and alters the activity levels of 
antioxidative enzymes (Duan et al., 2016a; Duan et al., 2016b). Here we suggest that NP exposure is capable of inducing oxidative protein damage, which if not removed, could accumulate over time and cause deterioration of testicular cell function.

Some studies confirm that NP exposure could alter the enzymes of carbohydrate metabolism and negatively impact carbohydrate metabolism in the animal's liver (Jubendradass et al., 2012; Yang et al., 2017). Phosphate serves as a transmitter of biological signals and plays a central role in increasing the turnover rates of cellular enzymes (Cassago et al., 2012). Accordingly, we calculated the intensity ratio of phosphate-to-carbohydrate which serves as a potential biomarker to identify metabolic changes (Theophilou et al., 2016; Paraskevaidi et al., 2017a). Prominently, NP exposure provoked decreases of phosphate-to-carbohydrate ratio in testicular cells from rats of 21- or 35-days-old classes and in primary SCs (Figure 3D and 7D). The crucial roles of AMPK/Akt in the regulation of cellular metabolism have been well documented (Mihaylova and Shaw, 2011; Yu and Cui, 2016). Moreover, NP-induced changes in AMPK/Akt-mediated pathways possibly contribute to testicular toxicity and spermatogenesis impairment (Huang et al., 2016; Duan et al., 2017b; Su et al., 2018). In the light of these observations, we propose that NP exposure alters the metabolic programming of the cell fate by regulating signalling molecules important for testicular development.

Between the seminiferous tubules lies the interstitial tissue, a loose connective tissue mainly containing the steroidogenic Leydig cells. The Leydig cells produce testosterone, which in turn stimulates SCs to secrete a wide variety of factors required for the proliferation and differentiation of germ cells. Treatment with NP resulted in decreases in serum testosterone levels in male rats (Aly et al., 2012; Huang et al., 2016; Duan et al., 2017a), which was probably caused by Leydig cell dysfunction. Raman spectroscopy was successfully employed to interrogate the testis interstitium in this study. Our results show that NP exposure generated a range of biomolecular alterations related to structural proteins and lipids/fatty acids. Also, results highlight marked variations in the ratio of lipid-to-protein and the levels of unsaturated lipids 
and saturated lipids in response to NP treatment (Figure 5). There are abundant lipid droplets visible in the cytoplasm of immature Leydig cells. Leydig cell lipid droplets primarily contain cholesterol esters; this cholesterol is the major source of cholesterol for androgen biosynthesis (Ma et al., 2018). Possibly, NP alters essential constituents of cell membranes resulting in Leydig cell injury, subsequently damaging the cellular biomolecules such as functional lipids. One of the effects observed in our experiments with NP treatments was the alterations in bands related to phospholipids. Phospholipids have been implicated in metabolic events associated with cell structure and function (Yang et al., 2012). From these findings, we conclude that NP exposure appears to act as a lipid metabolism disrupter, inducing deleterious effects in Leydig cells via metabolic perturbations and membrane disruption, and therefore, resulting in decreased output of testosterone and adversely influencing spermatogenesis.

In this work, both IR and Raman spectra indicate that NP can induce alterations in DNA/RNA. Particularly, the observed modifications in the pattern of DNA could suggest a genotoxic effect of NP in SCs and Leydig cells. Recently, NP has been reported to induce genotoxicity by inducing hepatic DNA fragmentation or DNA damage in different organs of C. punctatus (Sharma and Chadha, 2017; Sayed and Soliman, 2018). DNA damage, which could result in genome instability and apoptosis, could be a consequence of oxidative stress. At the cellular level, NP may stimulate the formation of reactive oxygen species, resulting in oxidative stress (Gong and Han, 2006; Duan et al., 2016b). Based on this evidence, we demonstrate that NP may interfere with cellular metabolism, and this effect coincides with potential DNA damage in testicular cells although the exact mechanism remains unknown.

The proportion and the differentiation (immature and mature cells) state of each cell population in the testis varies considerably between the 21-, 35- and 50-day-old rats. From our results of two-way ANOVA analysis, we identify a number of biomolecular parameters that are altered by the age $\times$ treatment statistical interaction (Figure S7, 9, 12 and 14). These interaction effects indicate that the status of testicular cell metabolism (growth, maintenance, and biomolecular composition) 
554 affects downstream cell signalling events in response to NP exposure, and the 555 exposure life-stage likely exerts independent effects on spectral features of testicular 556 cells. Specifically, the Raman results show that the 21- or 35-day-old rats responded 557 to the NP treatment highlighting the same bands at $997 \mathrm{~cm}^{-1}, 1007 \mathrm{~cm}^{-1}, 1200 \mathrm{~cm}^{-1}$ 558 and $1465 \mathrm{~cm}^{-1}$ although with different intensities (Figure 4G-H). However, the rats at 559 the three ages share no common spectral peaks in response to NP exposure. Moreover, 560 the peaks corresponding to lipids/fatty acids responses of 21-day-old NP-treated rats 561 are much more extensive than those of the 35- or 50-day-old rats treated with NP. 562 Differences among three age classes can be ascribed to testicular cells at different 563 development stages that exhibit alterations in biomolecular components and properties, resulting in different spectral characteristics induced by the same NP treatment.

\section{Conclusions}

566

567

568

569

570

571

572

573

574

575

Testicular biomolecular alterations in the intensity of spectral bands following NP treatment indicate effects on cellular metabolism and membrane integrity. ATR-FTIR and Raman spectroscopy are complementary vibrational spectroschemical techniques, which allow the discrimination and quantitative characterization of different peaks and targeted areas between NP-treated and untreated rats at different ages. Biomolecular differences were noted after NP administration in rats: proteins (1416 $\left.\mathrm{cm}^{-1}\right)$, Amide I $\left(1667,1670 \mathrm{~cm}^{-1}\right)$, Amide II $\left(1582,1504,1497 \mathrm{~cm}^{-1}\right)$, fatty acids $(1732$ $\left.\mathrm{cm}^{-1}\right)$, RNA $\left(1111 \mathrm{~cm}^{-1}\right)$ in IR spectra from testicular cells; and lipids $\left(1465 \mathrm{~cm}^{-1}\right)$, phospholipids $\left(1650,997 \mathrm{~cm}^{-1}\right)$, nucleic acid bands $\left(1485,1200 \mathrm{~cm}^{-1}\right)$, phenylalanine $\left(1007 \mathrm{~cm}^{-1}\right)$, DNA $\left(1334,1184 \mathrm{~cm}^{-1}\right)$ in Raman spectra from interstitial tissue. Intriguingly, NP has different effects on testicular cellular components depending on the age of the animal at the time of exposure. Moreover, we observed NP-induced spectral changes in SCs, which are mainly assigned to Amide II, DNA and lipid CH stretching. This study could be the basis for future investigations lending new insights into our understanding of the mechanisms of NP-induced testicular toxicity in rats.

\section{Acknowledgements}


583 This work was supported by the China Postdoctoral Science Foundation (nos. 584 2016M602310) and the Doctoral Startup Project of Hubei University of Medicine 585 (nos. 2017QDJZR07).

586

587 Conflict of interest

588 The authors declare that there are no conflicts of interest.

589 
591 Aly, H.A., Domenech, O., Banjar, Z.M., 2012. Effect of nonylphenol on male reproduction: analysis of

592

593

594

595

596

597

598

599

600

601

602

603

604

605

606

607

608

609

610

611

612

613

614

615

616

617

618

619

620

621

622

623

624

625

626

627

628

629

630

631

632

rat epididymal biochemical markers and antioxidant defense enzymes. Toxicology and Applied Pharmacology 261, 134-141.

Andrew Chan, K.L., Kazarian, S.G., 2016. Attenuated total reflection Fourier-transform infrared (ATR-FTIR) imaging of tissues and live cells. Chemical Society reviews 45, 1850-1864.

Aparicio, I., Martin, J., Abril, C., Santos, J.L., Alonso, E., 2017. Determination of household and industrial chemicals, personal care products and hormones in leafy and root vegetables by liquid chromatography-tandem mass spectrometry. Journal of chromatography. A.

Asimakopoulos, A.G., Thomaidis, N.S., Koupparis, M.A., 2012. Recent trends in biomonitoring of bisphenol A, 4-t-octylphenol, and 4-nonylphenol. Toxicology letters 210, 141-154.

Baker, M.J., Trevisan, J., Bassan, P., Bhargava, R., Butler, H.J., Dorling, K.M., Fielden, P.R., Fogarty, S.W., Fullwood, N.J., Heys, K.A., Hughes, C., Lasch, P., Martin-Hirsch, P.L., Obinaju, B., Sockalingum, G.D., Sule-Suso, J., Strong, R.J., Walsh, M.J., Wood, B.R., Gardner, P., Martin, F.L., 2014. Using Fourier transform IR spectroscopy to analyze biological materials. Nat Protoc 9, 1771-1791.

Butler, H.J., Ashton, L., Bird, B., Cinque, G., Curtis, K., Dorney, J., Esmonde-White, K., Fullwood, N.J., Gardner, B., Martin-Hirsch, P.L., Walsh, M.J., McAinsh, M.R., Stone, N., Martin, F.L., 2016. Using Raman spectroscopy to characterize biological materials. Nature protocols 11, 664-687.

Cassago, A., Ferreira, A.P., Ferreira, I.M., Fornezari, C., Gomes, E.R., Greene, K.S., Pereira, H.M., Garratt, R.C., Dias, S.M., Ambrosio, A.L., 2012. Mitochondrial localization and structure-based phosphate activation mechanism of Glutaminase $C$ with implications for cancer metabolism. Proceedings of the National Academy of Sciences of the United States of America 109, 1092-1097.

Chapin, R.E., Delaney, J., Wang, Y., Lanning, L., Davis, B., Collins, B., Mintz, N., Wolfe, G., 1999. The effects of 4-nonylphenol in rats: a multigeneration reproduction study. Toxicological sciences : an official journal of the Society of Toxicology 52, 80-91.

Chen, J., Xiao, H.J., Qi, T., Chen, D.L., Long, H.M., Liu, S.H., 2015. Rare earths exposure and male infertility: the injury mechanism study of rare earths on male mice and human sperm. Environmental science and pollution research international 22, 2076-2086.

Cheng, Y., Shan, Z., Zhou, J., Bu, Y., Li, P., Lu, S., 2017. Effects of 4-nonylphenol in drinking water on the reproductive capacity of Japanese quails (Coturnix japonica). Chemosphere 175, 219-227.

Deng, P., Zhong, D., Nan, F., Liu, S., Li, D., Yuan, T., Chen, X., Zheng, J., 2010. Evidence for the bioactivation of 4-nonylphenol to quinone methide and ortho-benzoquinone metabolites in human liver microsomes. Chemical research in toxicology 23, 1617-1628.

Diao, P., Chen, Q., Wang, R., Sun, D., Cai, Z., Wu, H., Duan, S., 2017. Phenolic endocrine-disrupting compounds in the Pearl River Estuary: Occurrence, bioaccumulation and risk assessment. The Science of the total environment 584-585, 1100-1107.

Duan, P., Hu, C., Butler, H.J., Quan, C., Chen, W., Huang, W., Tang, S., Zhou, W., Yuan, M., Shi, Y., Martin, F.L., Yang, K., 2016a. Effects of 4-nonylphenol on spermatogenesis and induction of testicular apoptosis through oxidative stress-related pathways. Reproductive toxicology 62, 27-38.

Duan, P., Hu, C., Butler, H.J., Quan, C., Chen, W., Huang, W., Tang, S., Zhou, W., Yuan, M., Shi, Y., Martin, F.L., Yang, K., 2017a. 4-Nonylphenol induces disruption of spermatogenesis associated with oxidative stress-related apoptosis by targeting p53-Bcl-2/Bax-Fas/FasL signaling. Environmental toxicology 32, 739-753. 
Duan, P., Hu, C., Quan, C., Yu, T., Huang, W., Chen, W., Tang, S., Shi, Y., Martin, F.L., Yang, K., $2017 \mathrm{~b}$. 4-Nonylphenol induces autophagy and attenuates mTOR-p70S6K/4EBP1 signaling by modulating AMPK activation in Sertoli cells. Toxicol Lett 267, 21-31.

Duan, P., Hu, C., Quan, C., Yu, T., Zhou, W., Yuan, M., Shi, Y., Yang, K., 2016b. 4-Nonylphenol induces apoptosis, autophagy and necrosis in Sertoli cells: Involvement of ROS-mediated AMPK/AKT-mTOR and JNK pathways. Toxicology 341-343, 28-40.

Eberhardt, K., Stiebing, C., Matthaus, C., Schmitt, M., Popp, J., 2015. Advantages and limitations of Raman spectroscopy for molecular diagnostics: an update. Expert review of molecular diagnostics 15 , 773-787.

El-Sayed Ali, T., Abdel-Aziz, S.H., El-Sayed, A.F., Zeid, S., 2014. Structural and functional effects of early exposure to 4-nonylphenol on gonadal development of Nile tilapia (Oreochromis niloticus): a-histological alterations in ovaries. Fish physiology and biochemistry 40, 1509-1519.

Fairbairn, D.J., Karpuzcu, M.E., Arnold, W.A., Barber, B.L., Kaufenberg, E.F., Koskinen, W.C., Novak, P.J., Rice, P.J., Swackhamer, D.L., 2016. Sources and transport of contaminants of emerging concern: $A$ two-year study of occurrence and spatiotemporal variation in a mixed land use watershed. The Science of the total environment 551-552, 605-613.

Gajjar, K., Heppenstall, L.D., Pang, W., Ashton, K.M., Trevisan, J., Patel, II, Llabjani, V., Stringfellow, H.F., Martin-Hirsch, P.L., Dawson, T., Martin, F.L., 2012. Diagnostic segregation of human brain tumours using Fourier-transform infrared and/or Raman spectroscopy coupled with discriminant analysis. Analytical methods : advancing methods and applications 5, 89-102.

Gong, Y., Han, X.D., 2006. Nonylphenol-induced oxidative stress and cytotoxicity in testicular Sertoli cells. Reproductive toxicology 22, 623-630.

Heppenstall, L.D., Strong, R.J., Trevisan, J., Martin, F.L., 2013. Incorporation of deuterium oxide in MCF-7 cells to shed further mechanistic insights into benzo[a]pyrene-induced low-dose effects discriminated by ATR-FTIR spectroscopy. The Analyst 138, 2583-2591.

Huang, W., Quan, C., Duan, P., Tang, S., Chen, W., Yang, K., 2016. Nonylphenol induced apoptosis and autophagy involving the Akt/mTOR pathway in prepubertal Sprague-Dawley male rats in vivo and in vitro. Toxicology 373, 41-53.

Iqbal, M., Bhatti, I.A., 2015. Gamma radiation/H2O2 treatment of a nonylphenol ethoxylates: Degradation, cytotoxicity, and mutagenicity evaluation. Journal of hazardous materials 299, 351-360. Jambor, T., Tvrda, E., Tusimova, E., Kovacik, A., Bistakova, J., Forgacs, Z., Lukac, N., 2017. In vitro effect of 4-nonylphenol on human chorionic gonadotropin (hCG) stimulated hormone secretion, cell viability and reactive oxygen species generation in mice Leydig cells. Environmental pollution 222, 219-225. Jin, N., Paraskevaidi, M., Semple, K.T., Martin, F.L., Zhang, D., 2017. Infrared Spectroscopy Coupled with a Dispersion Model for Quantifying the Real-Time Dynamics of Kanamycin Resistance in Artificial Microbiota. Analytical chemistry 89, 9814-9821.

Jubendradass, R., D'Cruz, S.C., Mathur, P.P., 2012. Long-term exposure to nonylphenol affects insulin signaling in the liver of adult male rats. Human \& experimental toxicology $31,868-876$.

Lee, H.R., Jeung, E.B., Cho, M.H., Kim, T.H., Leung, P.C., Choi, K.C., 2013. Molecular mechanism(s) of endocrine-disrupting chemicals and their potent oestrogenicity in diverse cells and tissues that express oestrogen receptors. Journal of cellular and molecular medicine 17, 1-11.

Li, H., Martin, F.L., Zhang, D., 2017. Quantification of Chemotaxis-Related Alkane Accumulation in Acinetobacter baylyi Using Raman Microspectroscopy. Analytical chemistry 89, 3909-3918.

Li, J., Strong, R., Trevisan, J., Fogarty, S.W., Fullwood, N.J., Jones, K.C., Martin, F.L., 2013a. Dose-related 
alterations of carbon nanoparticles in mammalian cells detected using biospectroscopy: potential for real-world effects. Environmental science \& technology 47, 10005-10011.

Li, J., Tian, M., Cui, L., Dwyer, J., Fullwood, N.J., Shen, H., Martin, F.L., 2016. Low-dose carbon-based nanoparticle-induced effects in A549 lung cells determined by biospectroscopy are associated with increases in genomic methylation. Scientific reports 6, 20207.

Li, J., Ying, G.G., Jones, K.C., Martin, F.L., 2015. Real-world carbon nanoparticle exposures induce brain and gonadal alterations in zebrafish (Danio rerio) as determined by biospectroscopy techniques. The Analyst 140, 2687-2695.

Li, X., Ying, G.G., Zhao, J.L., Chen, Z.F., Lai, H.J., Su, H.C., 2013b. 4-Nonylphenol, bisphenol-A and triclosan levels in human urine of children and students in China, and the effects of drinking these bottled materials on the levels. Environment international 52, 81-86.

Lima, K.M., Gajjar, K.B., Martin-Hirsch, P.L., Martin, F.L., 2015. Segregation of ovarian cancer stage exploiting spectral biomarkers derived from blood plasma or serum analysis: ATR-FTIR spectroscopy coupled with variable selection methods. Biotechnology progress 31, 832-839.

Lin, C.C., Chien, C.J., Tsai, M.S., Hsieh, C.J., Hsieh, W.S., Chen, P.C., 2017. Prenatal phenolic compounds exposure and neurobehavioral development at 2 and 7 years of age. The Science of the total environment 605-606, 801-810.

Liu, X., Nie, S., Chen, Y., Huang, D., Xie, M., 2014. Effects of 4-nonylphenol isomers on cell receptors and mitogen-activated protein kinase pathway in mouse Sertoli TM4 cells. Toxicology 326, 1-8.

Lu, Y., Luo, B., Li, J., Dai, J.Y., 2016. Perfluorooctanoic acid disrupts the blood-testis barrier and activates the TNF alpha/p38 MAPK signaling pathway in vivo and in vitro. Arch Toxicol 90, 971-983.

Ma, Y., Zhou, Y., Zhu, Y.C., Wang, S.Q., Ping, P., Chen, X.F., 2018. Lipophagy Contributes to Testosterone Biosynthesis in Male Rat Leydig Cells. Endocrinology 159, 1119-1129.

Mihaylova, M.M., Shaw, R.J., 2011. The AMPK signalling pathway coordinates cell growth, autophagy and metabolism. Nature cell biology 13, 1016-1023.

Noorimotlagh, Z., Haghighi, N.J., Ahmadimoghadam, M., Rahim, F., 2017. An updated systematic review on the possible effect of nonylphenol on male fertility. Environmental science and pollution research international 24, 3298-3314.

Obinaju, B.E., Fullwood, N.J., Martin, F.L., 2015. Distinguishing nuclei-specific benzo[a]pyrene-induced effects from whole-cell alterations in MCF-7 cells using Fourier-transform infrared spectroscopy. Toxicology 335, 27-34.

Obinaju, B.E., Martin, F.L., 2016. ATR-FTIR spectroscopy reveals polycyclic aromatic hydrocarbon contamination despite relatively pristine site characteristics: Results of a field study in the Niger Delta. Environment international 89-90, 93-101.

Owens, G.L., Gajjar, K., Trevisan, J., Fogarty, S.W., Taylor, S.E., Da Gama-Rose, B., Martin-Hirsch, P.L., Martin, F.L., 2014. Vibrational biospectroscopy coupled with multivariate analysis extracts potentially diagnostic features in blood plasma/serum of ovarian cancer patients. Journal of biophotonics 7 , 200-209.

Paraskevaidi, M., Morais, C.L.M., Lima, K.M.G., Snowden, J.S., Saxon, J.A., Richardson, A.M.T., Jones, M., Mann, D.M.A., Allsop, D., Martin-Hirsch, P.L., Martin, F.L., 2017a. Differential diagnosis of Alzheimer's disease using spectrochemical analysis of blood. Proceedings of the National Academy of Sciences of the United States of America 114, E7929-E7938.

Paraskevaidi, M., Morais, C.L.M., Lima, K.M.G., Snowden, J.S., Saxon, J.A., Richardson, A.M.T., Jones, M., Mann, D.M.A., Allsop, D., Martin-Hirsch, P.L., Martin, F.L., 2017b. Differential diagnosis of Alzheimer's 
disease using spectrochemical analysis of blood. Proceedings of the National Academy of Sciences of the United States of America 114, E7929-E7938.

Pastor-Belda, M., Vinas, P., Campillo, N., Hernandez-Cordoba, M., 2017. Magnetic solid phase extraction with CoFe2O4/oleic acid nanoparticles coupled to gas chromatography-mass spectrometry for the determination of alkylphenols in baby foods. Food chemistry 221, 76-81.

Peng, F.J., Pan, C.G., Zhang, M., Zhang, N.S., Windfeld, R., Salvito, D., Selck, H., Van den Brink, P.J., Ying, G.G., 2017. Occurrence and ecological risk assessment of emerging organic chemicals in urban rivers: Guangzhou as a case study in China. The Science of the total environment 589, 46-55.

Riding, M.J., Martin, F.L., Trevisan, J., Llabjani, V., Patel, II, Jones, K.C., Semple, K.T., 2012. Concentration-dependent effects of carbon nanoparticles in gram-negative bacteria determined by infrared spectroscopy with multivariate analysis. Environmental pollution 163, 226-234.

Sayed, A.E.H., Soliman, H.A.M., 2018. Modulatory effects of green tea extract against the hepatotoxic effects of 4-nonylphenol in catfish (Clarias gariepinus). Ecotoxicology and environmental safety 149, 159-165.

Sharma, M., Chadha, P., 2017. Widely used non-ionic surfactant 4-nonylphenol: showing genotoxic effects in various tissues of Channa punctatus. Environmental science and pollution research international 24, 11331-11339.

Soares, A., Guieysse, B., Jefferson, B., Cartmell, E., Lester, J.N., 2008. Nonylphenol in the environment: a critical review on occurrence, fate, toxicity and treatment in wastewaters. Environment international 34, 1033-1049.

Staniszewska, M., Nehring, I., Mudrak-Cegiolka, S., 2016. Changes of concentrations and possibility of accumulation of bisphenol $\mathrm{A}$ and alkylphenols, depending on biomass and composition, in zooplankton of the Southern Baltic (Gulf of Gdansk). Environmental pollution 213, 489-501.

Strong, R.J., Halsall, C.J., Jones, K.C., Shore, R.F., Martin, F.L., 2016. Infrared spectroscopy detects changes in an amphibian cell line induced by fungicides: Comparison of single and mixture effects. Aquatic toxicology $178,8-18$.

Su, Y., Quan, C., Li, X., Shi, Y., Duan, P., Yang, K., 2018. Mutual promotion of apoptosis and autophagy in prepubertal rat testes induced by joint exposure of bisphenol $A$ and nonylphenol. Environmental pollution $243,693-702$.

Theophilou, G., Lima, K.M., Martin-Hirsch, P.L., Stringfellow, H.F., Martin, F.L., 2016. ATR-FTIR spectroscopy coupled with chemometric analysis discriminates normal, borderline and malignant ovarian tissue: classifying subtypes of human cancer. The Analyst 141, 585-594.

Wang, B., Dong, F., Chen, S., Chen, M., Bai, Y., Tan, J., Li, F., Wang, Q., 2016. Phenolic endocrine disrupting chemicals in an urban receiving river (Panlong river) of Yunnan-Guizhou plateau: Occurrence, bioaccumulation and sources. Ecotoxicology and environmental safety 128, 133-142.

Wu, J., Wang, F., Gong, Y., Li, D., Sha, J., Huang, X., Han, X., 2009. Proteomic analysis of changes induced by nonylphenol in Sprague-Dawley rat Sertoli cells. Chemical research in toxicology 22 , 668-675.

Xin, X., Huang, G., Liu, X., An, C., Yao, Y., Weger, H., Zhang, P., Chen, X., 2017. Molecular toxicity of triclosan and carbamazepine to green algae Chlorococcum sp.: A single cell view using synchrotron-based Fourier transform infrared spectromicroscopy. Environmental pollution 226, 12-20. Yang, J., Yu, J., Wang, P., Luo, Y., Yang, X.F., Yang, X.S., Li, W.M., Xu, J., 2017. The adverse effects of perinatal exposure to nonylphenol on carbohydrate metabolism in male offspring rats. Int $J$ Environ Health Res 27, 368-376. 

2012. The proteomics of lipid droplets: structure, dynamics, and functions of the organelle conserved from bacteria to humans. Journal of lipid research 53, 1245-1253. Yonar, D., Ocek, L., Tiftikcioglu, B.I., Zorlu, Y., Severcan, F., 2018. Relapsing-Remitting Multiple Sclerosis diagnosis from cerebrospinal fluids via Fourier transform infrared spectroscopy coupled with multivariate analysis. Scientific reports 8, 1025. Yousef, I., Seksek, O., Gil, S., Prezado, Y., Sule-Suso, J., Martinez-Rovira, I., 2016. Study of the biochemical effects induced by X-ray irradiations in combination with gadolinium nanoparticles in F98 glioma cells: first FTIR studies at the Emira laboratory of the SESAME synchrotron. The Analyst 141, 2238-2249. Yu, J.S., Cui, W., 2016. Proliferation, survival and metabolism: the role of PI3K/AKT/mTOR signalling in pluripotency and cell fate determination. Development 143, 3050-3060. 
779

780

781

782

783

784

Figure 1. PCA-LDA of IR spectral data extracted from the testicular cells of rats exposed to 4-Nonylphenol (NP) at each concentration vs. control. Three-dimensional (3-D) PCA-LDA scores plots for IR spectral regions of 1800-900 $\mathrm{cm}^{-1}$ (A) and of 3200-2800 $\mathrm{cm}^{-1}$ (B). Linear discriminant 1 (LD1) scatter plots from PCA-LDA for IR spectral regions of $1800-900 \mathrm{~cm}^{-1}$ (C) and of $3200-2800 \mathrm{~cm}^{-1}$ (D). Confidence ellipsoids (90\%) were drawn in each 3D scores plot. The data of each LD1 scatter plot is represented as mean \pm standard deviations. $n=6$ for each group. Significance of category segregation was determined using one-way ANOVA with the Fisher's LSD or Dunnett's T3 post-hoc test, ${ }^{* * *} P<0.001$ vs. the control group (0 $\mathrm{mg} / \mathrm{kg} \mathrm{NP})$.

Figure 2. Cluster vectors plots comparing the control (red line at origin) and 4-Nonylphenol (NP)-treated groups. (A) 21-day-old rats; (B) 35-day-old rats; (C) 50-day-old rats. The spectra cut at 1800-900 $\mathrm{cm}^{-1}$ (left column) were baseline-corrected and normalized to the Amide I peak prior to PCA-LDA. The spectra cut between 3100 and $2800 \mathrm{~cm}^{-1}$ (right column) were baseline-corrected and vector-normalized. Plots were generated following PCA-LDA and show the top eight discriminating wavenumbers $\left(\mathrm{cm}^{-1}\right)$ responsible for the separation between NP exposure and control groups $(0 \mathrm{mg} / \mathrm{kg} \mathrm{NP})$. Data represent the average of six rats per group.

Figure 3. Comparison of discriminating wavenumbers $\left(\mathrm{cm}^{-1}\right)$ with tentative biomolecular assignments between control and 4-Nonylphenol (NP)-treated groups. IR spectra were from the testicular cells of mice exposed to different concentrations of NP. (A) Lipid-to-protein ratio $\left(1740 \mathrm{~cm}^{-1} / 1400 \mathrm{~cm}^{-1}\right.$ ratio); (B) Peptide aggregation (1630 $\mathrm{cm}^{-1} / 1650 \mathrm{~cm}^{-1}$ ratio); (C) Amide I-to-Amide II ratio (1655 $\mathrm{cm}^{-1} / 1545 \mathrm{~cm}^{-1}$ ratio); (D) Phosphate-to-carbohydrate ratio [(1055-1045) $\mathrm{cm}^{-1} /(1555-1535) \mathrm{cm}^{-1}$ ratio]. All the data are represented as mean \pm standard deviation. $n=6$ for each group. ${ }^{*} P<0.05, * * P<0.01, * * * P<0.001$ vs. control group ( 0 
mg/kg NP), one-way ANOVA with the Fisher's LSD or Dunnett's T3 post-hoc test.

Figure 4. PCA-LDA and resultant cluster vectors plots for Raman spectra extracted from testicular interstitial tissue in rats treated with 4-Nonylphenol (NP) and untreated. (A) Top row: 21-day-old rats. (B) Middle row: 35-day-old rats. (C) Bottom row: 50-day-old rats. Three-dimensional (3-D) PCA-LDA scores plots (A, B and C), Linear discriminant 1 (LD1) scatter plots (D, E and F), cluster vectors plots (G, $\mathbf{H}$ and $\mathbf{I}$ ), for Raman spectra region at 1800-900 $\mathrm{cm}^{-1}$ (fingerprint region). Spectra were baseline-corrected and normalized to the Amide I peak. Confidence ellipsoids (90\%) were drawn in each 3D scores plot. The data of each LD1 scatter plot is represented as mean \pm standard deviation. Cluster vectors plots were generated following PCA-LDA and show the top eight discriminating wavenumbers responsible for the separation between NP exposure and control groups. Data represent the average of six mice per group. Significance of category segregation was determined using one-way ANOVA with the Fisher's LSD or Dunnett's T3 post-hoc test, $* * * P<0.001 v s$. control group $(0 \mathrm{mg} / \mathrm{kg} \mathrm{NP})$.

Figure 5. Comparison of discriminating wavenumbers $\left(\mathrm{cm}^{-1}\right)$ with tentative biochemical assignments between control and 4-Nonylphenol (NP)-treated groups. Raman spectra were from the testicular interstitial tissue of mice exposed to different concentrations of NP. (A) Protein-to-lipid ratio $\left(1650 \mathrm{~cm}^{-1} / 1440 \mathrm{~cm}^{-1}\right.$ ratio); (B) Unsaturated lipids (1654 $\mathrm{cm}^{-1} / 1445 \mathrm{~cm}^{-1}$ ratio); (C) Saturated lipids (1303 $\mathrm{cm}^{-1} / 1267 \mathrm{~cm}^{-1}$ ratio). All the data are represented as mean \pm standard deviation. $n=6$ for each group. ${ }^{*} P<0.05, * * P<0.01, * * * P<0.001 v s$. control group ( $0 \mathrm{mg} / \mathrm{kg} \mathrm{NP}$ ), one-way ANOVA with the Fisher's LSD or Dunnett's T3 post-hoc test.

Figure 6. PCA-LDA scores plots and resultant cluster vectors plots for IR spectra acquired from Sertoli cells exposed to 4-nonylphenol (NP) at various doses $(2.5,5,10$ and $20 \mu M)$ compared to the control $(0 \mu M ~ N P)$. Upper row: two-dimensional (2D) PCA-LDA scores plot of Linear discriminant 1 (LD1) vs. Linear discriminant 2 (LD2) (A), LD1 scatter plots (C) and cluster vectors plots (E) for IR spectral region at $1800-900 \mathrm{~cm}^{-1}$ with baseline-correction and normalization to 
835 the Amide I peak $\left(1650 \mathrm{~cm}^{-1}\right)$. Lower row: an expanded view (B, D and F) of the CH 836 stretching region 3100-2800 $\mathrm{cm}^{-1}$, baseline-corrected and vector-normalized. 837 Confidence ellipsoids $(90 \%)$ were drawn in each 2-D scores plot. The data of each 838 LD1 scatter plot is represented as mean \pm standard deviation of three experiments. 839 Cluster vectors plots were generated following PCA-LDA and show discriminating 840 wavenumbers. ${ }^{*} P<0.05, * * * P<0.001$ vs. control group (0 $\left.\mu \mathrm{M} \mathrm{NP}\right)$, one-way 841 ANOVA with the Fisher's LSD or Dunnett's T3 post-hoc test.

Figure 7. Comparison of discriminating wavenumbers $\left(\mathrm{cm}^{-1}\right)$ with tentative biochemical assignments between the control and 4-nonylphenol (NP)-treated Sertoli cells. IR spectra were from Sertoli cells treated with $0,2.5,5,10$ and $20 \mu \mathrm{M}$ NP for 12 h. (A) Lipid-to-protein ratio (1740 $\mathrm{cm}^{-1} / 1400 \mathrm{~cm}^{-1}$ ratio); (B) Peptide aggregation (1630 $\mathrm{cm}^{-1} / 1650 \mathrm{~cm}^{-1}$ ratio); (C) Amide I-to-Amide II ratio (1655 $847 \mathrm{~cm}^{-1} / 1545 \mathrm{~cm}^{-1}$ ratio); (D) Phosphate-to-carbohydrate ratio [(1055-1045) $848 \mathrm{~cm}^{-1} /(1555-1535) \mathrm{cm}^{-1}$ ratio]. All the data are represented as mean \pm standard 849 deviation of three experiments. ${ }^{*} P<0.05, * * P<0.01, * * * P<0.001 v s$. control group ( 0 850 mg/kg NP), one-way ANOVA with the Fisher's LSD or Dunnett's T3 post-hoc test. 